\title{
Psicanálise e música: contribuições do acalanto ao viver criativo
}

\author{
Psychoanalysis and music: contributions of calming to creative living
}

\section{Denise Sayuri Abe', Amanda Lays Monteiro Inácio², Maíra Bonafé Sei e Rosemarie Elizabeth Schimidt Almeida ${ }^{4}$}

Resumo: Ainda na fase intrauterina, o som já se encontra presente e o bebê pode captá-lo e sentilo em toda a extensão de seu corpo, principalmente a voz da mãe. O início da vida erige os alicerces da vida psíquica e, dada sua relevância, sob o vértice da psicanálise, buscamos apreender a atividade musical do acalanto, a qual deriva numa posição favorável na vida dos bebês. Freud e Winnicott assinalam que, ao nascer, o bebê é dependente de cuidados alheios. A mãe, para Freud, corresponde ao primeiro objeto de amor da criança assim como para Winnicott, ao dedicar-se à provisão ambiental indispensável ao viver. Assim, a presença do acalanto como um dos primeiros objetos culturais que a criança tem acesso, configura-se como um precursor de um dos fenômenos transicionais que demarcam a infância, e instrumentaliza a continuidade do "ser", como vetor da herança cultural. Realizou-se uma análise da animação Coco (2017), também com o intuito de corroborar por meio do método psicanalítico, a ênfase desse fenômeno. Depreendeu-se, que o valor atribuído ao acalanto não foi somente musical e cultural, mas traduziu -se em efeitos de integração no desenvolvimento do infante, uma vez que essa área intermediária de experiência, fortalece o vínculo primordial mãe-bebê e possibilitará um viver criativo.

Palavras-chave: Criatividade; Psicanálise; Winnicott.

Abstract: Even in the intrauterine phase, the sound is already present and the baby can pick it up and feel it over the entire length of his body, especially the mother's voice. The beginning of life establishes the foundations of psychic life and given its relevance, under the apex of psychoanalysis, we seek to apprehend the musical activity of calming, which derives in a favorable position in the lives of babies. Freud and Winnicott point out that, at birth, the baby is dependent on the care of others. The mother, for Freud, corresponds to the child's first love object as well as for Winnicott, by dedicating herself to the environmental provision indispensable to living. Thus, the presence of calming as one of the first cultural objects that the child has access to, is configured as a precursor to one of the transitional phenomena that demarcate childhood, and instrumentalizes the continuity of "being", as a

\footnotetext{
1 Especialista em Clínica Psicanalítica pela Universidade Estadual de Londrina, Psicóloga pela Universidade Estadual Paulista (UNESP). E-mail: mj_sayuri@yahoo.com.br

2 Mestre em Educação pelo Programa de Mestrado e Doutorado em Educação da Universidade Estadual de Londrina e Especialista em Clínica Psicanalítica pela mesma instituição. Psicóloga, Professora Assistente do Departamento de Psicologia e Psicanálise da Universidade Estadual de Londrina. E-mail: amandalmonteiro@uel.br

3 Doutora em Psicologia Clínica pela Pontifícia Universidade Católica de Campinas. Psicóloga, Professora Associada do Departamento de Psicologia e Psicanálise da Universidade Estadual de Londrina. Formação em Psicanálise. Orientadora, Supervisora e Coordenadora do Curso de Especialização em Clínica Psicanalítica. E-mail: rosemarielizabeth@uel.br

${ }_{4}$ Mestrado, Doutorado e Pós-Doutorado em Psicologia Clínica pelo Instituto de Psicologia da Universidade de São Paulo. Psicóloga, Professora Adjunta do Departamento de Psicologia e Psicanálise e Orientadora do Programa de Pós-Graduação em Psicologia da Universidade Estadual de Londrina. E-mail: mairabonafe@gmail.com
} 
vector of cultural heritage. An analysis of the animation Coco (2017) was carried out, also with the intention of corroborating through the psychoanalytic method, the emphasis of this phenomenon. It emerged, that the value attributed to calming was not only musical and cultural but translated into effects of integration

\section{Introdução}

0 ser humano e sua elucidação para a Psicanálise, versam sobre o nascimento e as condições de sobrevivência do bebê, visto a fragilidade de suas características neo-natais. Em especial, destacam-se as relações primordiais fundantes da psique humana no processo maturacional. Outrossim, a arte e a cultura, agregam suas contribuições às singularidades da natureza humana. Assinala-se, portanto, a relevância do tema da experiência cultural quanto à formação constitutiva do sujeito. Do ponto de vista de um percurso desejável, averígua-se que isso se aplica em vista de um amadurecimento ativo de ser no mundo, dotado da plena capacidade de um viver criativo.

De que maneira o campo psicanalítico pode compreender esse fenômeno cultural intitulado acalanto, tão presente e arraigado em nossa civilização? Qual a contribuição que essa atividade musical pode oferecer à constituição psíquica do indivíduo, em especial, na condição de almejar que o sujeito ascenda à capacidade de um viver criativo? Por meio do método psicanalítico (Figueiredo \& Minerbo, 2006), torna-se possível assimilar um olhar sobre o fenômeno cultural do acalanto e atribuir-Ihe interpretaçōes sobre o marco fundante da subjetividade humana. É, pois, por meio desse método investigativo que se pretendeu tecer algumas considerações sobre a linguagem universal da música através do acalanto, um mito artístico que abarca a civilização desde seus primórdios, e que perpassa culturas e imprime singularidades que irão delinear os modos de existir no mundo, dos quais, neste estudo, destacaremos 0 viver criativo.

\section{Sobre 0 amadurecimento pessoal}

A teoria do amadurecimento pessoal diz respeito ao processo pelo qual transcorre o desenvolvimento do bebê até a vida adulta, cujas fases perpassam a dependência absoluta, a dependência relativa, e, aos poucos, atinge certa independência. Trata-se, portanto, dos diversos aspectos presentes na formação de uma pessoa e dos pormenores dos possíveis caminhos na travessia durante seu amadurecimento (Winnicott, 1960/1983). É fato que esses estágios não se apresentam de maneira precisa e, portanto, podem transitar ora progressivamente, ora regressivamente mesmo em um desenvolvimento saudável.

Winnicott (1960/1983) elucida que, em princípio, o lactente encontra-se em situação de dependência absoluta, momento em que se encontra frágil e desprovido de condições para sua sobrevivência. Identificada com o bebê e provida de capacidade adaptativa adequada, a mãe promoverá o decurso do processo maturacional dele contanto que ela ofereça, suficientemente, cuidados contínuos de forma adaptativa. Nesse estágio, 0 bebê não possui a percepção do zelo materno. 0 que se segue é que, conforme 0 bebê vai adquirindo confiança advinda da mãe suficientemente boa, através de seus sucessivos cuidados, ele poderá suportar as possíveis falhas dela, as quais serão in the infant's development, since this intermediate area of experience, strengthens the primordial bond between mother and baby and will enable a living creative.

Keywords: Creativity; Psychoanalysis; Winnicott.

imprescindíveis para que o lactente abandone sua crença onipotente na criação dos objetos e passe a apreendê-los, pouco a pouco, como externos a ele.

Ocorre que, nem direção ao estágio de dependência relativa, a criança "pode se dar conta da necessidade de detalhes do cuidado materno, e pode de modo crescente, relacioná-los ao impulso pessoal"; ou seja, mesmo que incipiente, há uma compreensão intelectual (Winnicott, 1960/1983, p. 46). Ao considerar a relevância da provisão ambiental realizada por meio dos cuidados dispensados pela mãe a seu bebê, Winnicott (1958/2011) apresenta o conceito de integração, cuja definição remete a uma unidade da personalidade, embora seja muito dependente e venha apresentada de forma progressiva a partir de um estado primeiro não-integrado.

Então, se há uma favorável adaptação materna às necessidades do bebê, isso proporciona uma facilitação em seu desenvolvimento para que psique e soma (personalização) estejam cada vez mais integrados e, então, ele possa suportar certas fal has ambientais necessárias ao progresso em curso. A partir de então, o lactente poderá deixar de ser junto à sua mãe, para ser um outro diferente dela, demarcando o princípio do processo de aceitação da alteridade (Winnicott, 1958/2011).

Dito isso, é por meio do apoio do ego materno que o bebê poderá garantir uma existência que partirá do "não-EU"ao "EU"e, posteriormente, diante das experiências de continuidade ofertadas pela mãe, vir a tornar-se"Eu sou". Esse estágio é fundamental para proporcionar ao bebê, futuramente, o "eu estou só", 0 qual corresponde a uma maturidade emocional da capacidade de estar só que somente é possível de se constituir, a princípio, na presença contínua da mãe (Rodrigues \& Peixoto Junior, 2017; Winnicott, 1967/2019).

Assegura-se, assim, que não há somente um nascimento concreto e biológico do bebê, mas também um nascimento psíquico, que será constituído a partir das provisões ambientais existentes. Elas tanto podem corresponder a um "ambiente suficientemente bom", que possibilita ao bebê alcançar, a cada etapa, as satisfações, ansiedades e conflitos inatos e pertinentes, ou até mesmo a um "ambiente não suficientemente bom", que pode distorcer 0 desenvolvimento do bebê (Winnicott, 1958/2011).

Tendo conquistado certa autonomia, é possivivel que o sujeito possa "ir vivendo sem cuidado real", 0 que equivale a supor que durante esse percurso, cujo início foi a dependência absoluta, ele desenvolveu meios de sobrevivência, passando, na sequência, pelo estágio de dependência relativa. Desta feita, apresenta-se, assim, o estágio "rumo à independência". É nesse ponto que o mundo externo vai ganhando mais espaço e, então, o indivíduo pode se identificar com a sociedade e nela se socializar. Nas palavras do autor, "isto é conseguido através do acúmulo das recordações do cuidado, da projeção de necessidades pessoais e da introjeção de detalhes do cuidado, com o desenvolvimento da confiança no meio" (Winnicott, 1960/1983, p. 46).

Em suma, é 0 olhar da mãe, aquela ocupada com preocupações mater- 
nas primárias, que olha e reflete o bebê (onipotente), que fará com que ele possa, progressivamente, constituir-se de maneira integrada. Poderá, assim, tornar-se um "vir a ser", com um verdadeiro self. Assim, ao bebê será possível, cronologicamente, superar a dependência absoluta e a dependência relativa para atingir um estágio rumo à independência, sendo este último desenvolvido ao longo de toda a vida (Winnicott, 1957/1999).

\section{Espaço potencial - objetos e fenômenos transicionais}

É fácil captarmos, a partir da simples observação, que a criança, desde muito nova, designa um objeto de possessão como seu fiel companheiro. Este, escolhido pela própria criança e contido de riqueza infinita, é denominado na teoria winnicottiana como objeto transicional (Winnicott, 1953/2019). 0 autor afirma que ao longo do desenvolvimento há uma tendência de que o bebê inclua objetos diferentes dele próprio em seu padrão pessoal, de modo que estes representam um objeto parcial, inicialmente relacionado ao seio materno. Ademais, esse objeto, característico do desenvolvimento emocional possui, paradoxalmente, valor de uma categoria que remete tanto ao self (mundo interior) quanto à realidade externa (mundo exterior) sem pertencer a nenhum deles, visto que se encontra no entremeio, sendo, portanto, intermediário.

A área intermediária, via de regra, é possivelmente adquirida a partir das experiências de separação do "EU"e do "não-EU"do bebê; ou seja, uma vez que haja um mundo interno e outro externo, opera-se, dialeticamente, um terceiro espaço de experiência que partilha desses dois mundos, denominado espaço potencial. Esse espaço, representante simultâneo da separação e da ligação entre mãe e bebê, que foi constituído e possibilitado pelos cuidados maternos favoráveis à adaptação contínua ao seu bebê, demarcará psiquicamente seu lugar no mundo por meio das experiências futuras e significativas que ele poderá obter no campo cultural (Fulgencio, 2016).

Ainda cedo, essa área intermediária ganha estatuto: é onde se encontram os objetos e fenômenos transicionais em que, posteriormente, tornar-se-á 0 espaço compartilhado do brincar. Ressalta-se que esse espaço intermediário de experiências, espaço potencial entre mãe e bebê, é singular a cada indivíduo, uma vez que é necessário considerar a gama de possibilidades de vivências entre a díade. Destaca-se ainda que essa intersecção entre o mundo interno e o mundo externo, onde se encontram os objetos e os fenômenos transicionais, apresenta-se como padrão, segundo Winnicott (1953/2019), por volta dos quatro e seis até os oito e doze meses de idade. No que concerne aos fenômenos transicionais, estes referem-se à fenômenos que perfazem o acervo da criança e, nas palavras do autor,

[...] o balbucio de um bebêe o modo como uma criança mais velha entoa um repertório de canções e melodias enquanto se prepara para dormir, incidem na área intermediária enquanto fenômenos transicionais juntamente com o uso que é dado a objetos que não fazem parte do corpo do bebê, embora ainda não sejam plenamente reconhecidos como pertencentes à realidade externa (Winnicott, 1975, p. 14).

Diante da definição exposta, evidencia-se que a prática do acalanto, que se localiza nessa área intermediária de experiência, tanto interna quanto externa, pode ser entendida neste estudo na qualidade de um fenômeno transicional, pois não se trata de um objeto e sim de um fenômeno que possui um lugar nas primeiras experiências de vida da criança. Outrossim, Winnicott (1953/2019) afirma que esses fenômenos abrigarão a experiência cultural do indivíduo.

É inegável a dimensão de preciosidade que a criança - mas não somente ela - designa a esses objetos e fenômenos transicionais, quer seja um ursinho, um brinquedo, após o uso do punho, do polegar. Os pais também reconhecem a sua importância, dado que, mesmo em viagens, não se esquecem de carregar esses pertences (Winnicott, 1953/2019), visto que os objetos e fenômenos transicionais carregam uma função relevante na vida de seu filho, pois é notória sua capacidade de apaziguar a angústia e ansiedade que possam vir a sentir, pois há uma função análoga com 0 acalanto.

Destaca-se ainda que o efeito apaziguador se deve ao fato de que, apesar de não ser o seio materno ou mesmo a mãe, em igual importância, 0 objeto vem a representá-los de forma satisfatória. A fruição das experiências de onipotência, experimentadas na confiança do bebê na mãe, no espaço potencial entre ela e o bebê" "Chamo isso de playground porque a brincadeira começa aqui" (Winnicott, 1971/2019, p. 83), que segue preparando o bebê para a fase seguinte, na qual a magia reflete-se pelo estado de confiança que superpõe duas áreas de brincadeira - da mãe e do bebê.

Representa a transição do bebê de um estado em que está fundido com a mãe para um estado em que está em relação com ela como algo externo e separado, o que fomentará a capacidade de adiar a gratificação e de lidar com a frustração, proporcionando, assim, a "capacidade de estar só". Essa capacidade pressupõe, portanto, as introjeções das canções de ninar (correspondentes a fenômenos transicionais) e os objetos transicionais, em seu mundo interno (Fulgencio, 2016; Winnicott, 1953/2019).

\section{O espaço musical: a voz da mãe e $o$ ato de acalantar}

Bjørkvold (2018a, 2018c), musicólogo e defensor da inserção musical nas escolas, compreende que a aprendizagem musical viabiliza uma via de expressão criativa para além da educação formal, em favor da emergência de um sujeito ativo, crítico e criativo que escapa à simples reprodução dos conteúdos aprendidos nas disciplinas escolares. Ele reforça a importância do aparelho sensorial de nosso corpo que, mesmo antes do nascimento, está impregnado de sensações que podem ser descritas em termos de"som, movimento e ritmo" (Bjørkvold, 2018a, p. 21), pois na barriga de sua mãe, segundo 0 autor, o bebêé capaz de responder aos movimentos dela, inclusive a partir de certa ritmação. Ele também é capaz de ouvir e captar os sons advindos tanto externamente ao ventre quanto internamente. Porém, não se trata, em absoluto, da capacidade de ouvir, uma vez que o som se propaga através de vibrações e, estando imerso no líquido amniótico, o bebê será capaz então de sentir em toda a extensão de seu corpo, a reverberação do som. Em suma, antes mesmo de chancelar a experiência sonora pela capacidade auditiva, ela é, sobretudo, corporal.

No texto As bases da formação do nascituro, um ponto marcante apresentado por Bjørkvold (2018a) é que se ressalta o valor do papel materno dando ênfase a sua voz. Algo inspirador acontece com o bebê quando ele tem como fundo sonoro as canções ouvidas na vida intrauterina e, mais tarde, também ao prosseguir ouvindo essa voz reconhecida como de sua mãe, nas músicas que 
ela entoa. 0 autor afirma que os primórdios da aprendizagem da linguagem se encontram nesse período, pois o bebê é atingido pela língua materna, em especial, pela voz da mãe, mesmo que essa voz não seja igualmente concebida após o seu nascimento. Ante 0 exposto, para 0 autor, 0 bebê não somente suga avidamente o leite como também a voz materna, uma língua musical em virtude de todas as suas nuances.

0 que se sucede no desenvolvimento dessa relação dual, é uma comunicação expressa por meio de tonalidades vocálicas do bebê para a sua mãe e, na língua musical materna, a aparição do "manhês", o qual se emprega uma "ampla gama de modulações de tom", cujo elemento que a desencadeia é 0 contato com o lactente (Bjørkvold, 2018b, p. 36). Ainda que, por parte do bebê, não haja uma linguagem propriamente dita, é possível verificar a premissa da comunicação ao nos depararmos com as adequações vocálicas que ele produz em reação às nuances de ritmo e andamento na voz materna, que o acalenta.

Para os fins a que se propõe o presente estudo, há que se fazer um esclarecimento prévio sobre a diferença terminológica da palavra acalanto e da expressão canção de ninar. Entende-se que o valor semântico do termo 'acalanto' produz maiores aproximações ao nosso campo de pesquisa, haja vista que pressupõe as ações de aquietar, confortar, embalar (Acalentar, 2020). Sobre essa premissa, é possível entender que a utilização da palavra acalanto seja mais apropriada aos interesses propostos nesse decurso, pois sugere a presença de outrem no processo de acalentar e, sendo assim, remete à existência da alteridade como condição fundamental para a constituição do sujeito e, consequentemente, à questões primordiais e fundantes da psique humana.

0 estudo de Machado (2012) faz uma interlocução entre literatura e psicologia ao desenvolver sua dissertação de doutorado sobre as canções de ninar brasileiras. A autora apresenta uma definição mais funcional para 0 acalanto e designa sua finalidade em adormecer crianças pequenas. Ademais, esse tipo de música tem reconhecido valor estético e pode ser considerado "como um dos primeiros objetos culturais, musical e literário, a que o ser humano é exposto" (Machado, 2012, p. 17). Há uma clara defesa em suas elucubrações para ampliar o principal sentido funcional dessas canções (atrelado ao adormecimento) ao compreender outras contribuições atinentes como sendo também veiculador de heranças e tradições culturais. Ou seja, nossas cantigas emanam da história de nosso país, com todas as influências demarcadas pelo seu povo de origem e pelos efeitos da escravidão e colonização, ganhando um status macro histórico social, cultural e étnico.

Na visão de Machado (2012), em termos gerais, essas cantigas, intimamente associadas à mãe e ao seu bebê, são conhecidas pelo seu aspecto de ingenuidade e, instantaneamente imaginadas no cerne da família. Além disso, sua pesquisa evidencia que esses fatos não contemplam a complexidade e totalidade da experiência do acalanto, uma vez que carrega também elementos culturais e, entrementes, amplia seu reduto para outros cuidadores, além da mãe. De maneira sintética, a autora conceitua e caracteriza esse gênero musical tendo em vista os seguintes aspectos: a brevidade ou curta extensão, a monotonia demarcada pelas repetições constantes e regularidades rítmicas e a utilidade para condução do sono.

Wolffenbüttel (2019), em sua pesquisa, realiza um levantamento bibliográfico sobre o tema do acalanto e ressalta a escassez de estudos a esse respeito. Assinala que, em geral, entre as características presentes nos acalantos, destaca-se a constatação de serem peças musicais curtas e singelas, cujo conteúdo e melodia são simples e exprimem uma forma pouco sofisticada de canto. Os adultos costumam enunciá-las de forma suave e por vezes repetitiva, a fim de induzir a criança ao sono ou a acalmar-se. A autora evidencia que essa prática pertence a quase todos os povos, incluindo os mais primitivos. A principal forma de transmissão é pela via da oralidade e as influências dos acalantos brasileiros são de origem africana, indígena e, principalmente, portuguesa. Ainda, há que se mencionar que a prática costuma ser seguida do embalo e de outros estímulos, transmitindo cuidado e afeto, que são incorporados junto a bagagem musical e cultural na adultez.

\section{Psicanálise e arte}

Freeland (2019a, p. 41) define a arte para a teoria da imitação, uma das teorias da arte, como "uma imitação da natureza ou da ação e da vida humana". Outras teorias, como a da expressão e a cognitiva, defendem que a "arte comunica: pode comunicar sentimentos e emoções ou pensamentos e ideias" (Freeland, 2019b, p. 147, grifo da autora).

No texto O delírio e os sonhos na Gradiva de W. Jensen, Freud (1907/2015) empreende uma análise por meio da obra literária Gradiva, do escritorWilhem Jensen (1837-1911), para realizar um estudo clínico acerca do personagem principal do romance. De acordo com Quinodoz (2007), o objetivo principal dessa publicação era validar as formulações metapsicológicas. Além disso, Freud busca entender quais motivos levam 0 artista a produzir uma obra artística e quais os impactos emocionais gerados ao seu espectador.

Freud (1913/2012), em O interesse científico da psicanálise, ressaltando 0 ponto de vista da ciência estética, compreende que a arte, em primeiro lugar, se destina ao apaziguamento dos desejos não satisfeitos de seu próprio criador e, posteriormente, de seus espectadores. 0 biógrafo de Freud, Peter Gay (2012), afirma que as pesquisas analíticas que Freud empreende no campo cultural, especificamente referente às obras de arte, diz respeito a "três dimensões principais da experiência estética: a psicologia dos protagonistas, a psicologia do público e a psicologia do autor" (Gay, 2012, p. 326). Para os fins propostos em nosso estudo, a dimensão realçada encontra-se atrelada à psicologia do público e diz respeito aos impactos produzidos àqueles que entram em contato com a produção artística, em especial, 0 acalanto.

Quem já cantou um acalanto para um bebê ou criança, assim como quem já presenciou tal situação, tem ciência de que algo é evocado àquele que, muitas vezes, ainda nem sabe se expressar por meio de palavras, apesar de que já se utilize de outros artifícios para sua expressão. No que tange a esse aspecto, relembramos o que Freud (1907/2015) afirma ao citar que "0 que realmente vale, na vida psíquica, são os sentimentos; as forças psíquicas todas têm importância apenas por sua capacidade de despertar sentimentos" (Freud, 1907/2015, p. 66-67).

Ante o exposto, compreendemos que, desde sua fundação, Psicanálise e Arte mantém uma interlocução profícua. Assim, inaugura-se um mar de possibilidades a ser explorado e investigado. Dito isso, depreendemos que a Música, inserida no campo artístico, oferta um vasto campo de conhecimento que é passível de apreensão pela Psicanálise. A partir dessa premissa, em uma perspectiva psicanalítica, juntam-se para serem analisados fragmentos do filme e da história retratada na animação intitulada Coco (2017), cujo nome em português corresponde à: Viva - a vida é uma festa.

E, mais especificamente, quanto ao acalanto, compreende-se que, ao servir como apaziguamento da ansiedade do lactente, contribui sobremaneira no processo de amadurecimento pessoal, visto que, por meio da atividade de 
acalantar, a mãe possibilita o aparecimento da confiança do lactente em uma continuidade de seu "ser" e, dessa forma, é fortalecido o vínculo mãe-bebê (Rodrigues \& Peixoto Junior, 2017; Winnicott, 1967/2019). Sabe-se que esse vínculo é 0 berço para as aquisições futuras do lactente, inclusive 0 acesso à capacidade de fruição artística a partir das experiências culturais. Dessa maneira, 0 acalanto entoado pela mãe não só carrega, em princípio, a potência do fenômeno transicional capaz de trazer alento como também, em etapa ulterior, expande o espaço potencial das experiências culturais e transmite a herança cultural, que poderá ser perpetuada de geração em geração e absorvidas pela sociedade como um patrimônio cultural.

\section{Método}

A Psicanálise, compreendida como uma disciplina científica, comporta bases epistemológicas e éticas para a realização de uma pesquisa. Desta feita, o presente estudo trata, por meio do aporte qualitativo, de uma pesquisa em psicanálise com o método psicanalítico (Figueiredo \& Minerbo, 2006). Esta modalidade possui, segundo os autores, um al cance bastante amplo, podendo se referir a processos socioculturais ou fenômenos psíquicos transcorridos e contemplados fora de uma situação analítica no sentido estrito.

Com base nesse método, há uma aproximação importante do pesquisador com o referencial teórico, que tem participação ativa em todo o processo de análise. Assim, entende-se que seja possível trazer contribuições à própria psicanálise enquanto área de conhecimento científico. Valendo-se de tal método, retoma-se também numa perspectiva psicanalítica, a análise de fragmentos do filme da história em animação intitulada Coco (2017), título o qual em português traduz-se como: Viva - a vida é uma festa.

\section{Resultados e discussão}

Utilizaremos o filme Coco (versão original), no Brasil intitulado Viva - a vida é uma festa (2017), a fim de, elucidativamente, elaborar al gumas reflexões a partir da análise de alguns fragmentos que enriquecem nossa discussão. A película corresponde a uma animação musical que, em 2018, foi premiada com o Oscar de Melhor filme de animação e Melhor canção original.

A psicanalista Vilete (2013), a o traçar um paralelo entre arte e psicanálise, afirma que o cinema tem, a seu favor, recursos técnicos que possibilitam anular a qualidade do tempo e do espaço como em um sonho e, dessa maneira, pode se comunicar diretamente ao inconsciente de seus espectadores através de sensações e afetos. Não à toa, verificamos cada vez mais o interesse de pesquisadores que se ocupam com esse tema e empregam o método psicanalítico como instrumento para apreender os processos psíquicos individuais e coletivos no campo das artes, seja pela literatura, pintura, dança, escultura, música ou mesmo pelo cinema. Esses fenômenos transicionais presentes na cultura facilitam o novo viver criativo, para além do efeito de sublimação, tão somente. Embora Freud (2015), questione: "Não deveríamos procurar os primeiros indícios da atividade poética já nas crianças? A atividade que mais agrada e a mais intensa das crianças é o brincar [...]" (p. 54).

No que se refere ao filme apontado acima, a animação ambienta-se no México e é carregada de referências à riqueza cultural do país, em especial, à celebração ao Dia dos Mortos. A história nos apresenta um garoto de 12 anos, Miguel Rivera, cujo sonho é se tornar cantor. Todavia, sua família baniu de sua vida a música, sendo proibida qualquer possibilidade de fruição de prazer por ela despertada após uma tragédia familiar que se perpetuou pelas gerações seguintes até alcançar o protagonista. Em busca de seu sonho, Miguel tem que enfrentar situações desafiantes e outras peripécias ao ser transportado, acidentalmente, a mundo dos mortos.

0 filme nos proporciona uma imersão no campo cultural do país, que é traduzido pelas imagens apresentadas na tela e pelo apelo musical de uma trilha sonora que envolve o telespectador nessa ambientação. Outra característica é que ele retrata com complexidade tanto a transmissão familiar quanto os conflitos geracionais que prendem a atenção do público infantil e adulto, de uma maneira singela, convincente, porquanto seus conteúdos remetem a conflitos e experiências inerentes à existência humana.

É pela experiência da área intermediária não contestada (área desenvolvida pelo brincar), ou seja, o campo relativo às artes, que o ser humano poderá aliviar essa tensão. Interessante notar que, ainda que Freud (1913/2012) e Winnicott (1971/2019) correlacionem a arte ao brincar e a um caminho intermediário entre a realidade externa e a interna, no entanto, há muitas distinções em suas asserções teóricas quanto ao tema.

Ao considerar o alinhamento teórico deste estudo à teoria winnicottiana, concedemos uma licença ao rigor acadêmico para expor a reflexão de que a atividade de dissertar se encontra no "reino intermediário potencial". Assim, norteados pelo aparato teórico apresentado e no intuito de expandir o campo de possibilidades de nossa capacidade interpretativa e criativa, ofertamos 0 convite ao brincar compartilhado ao prosseguirmos trançando os fios teóricos às pontas soltas dos fragmentos do filme que, nas linhas subsequentes, se produzem por meio da experimentação singular.

Retomando o enredo do filme, Miguel é apresentado como o protagonista da animação. Verifica-se, ainda, que a música possui papel fundamental na trama haja vista que ela é busca incessante do protagonista tal qual funciona como elemento narrativo da história por meio das letras das canções contidas na trilha sonora da película. Portanto, em nossa análise, consideramo-la, também, como protagonista da história. Em meio a um universo fictício e quase onírico, passado, presente e futuro são constantemente entrelaçados e evidenciados através dos contínuos flashbacks, das relações familiares que precedem e sucedem a Miguel e de sua pretensão a um futuro não predestinado.

0 protagonista/narrador explica que se sente castigado por algo que antecede seu nascimento e, então, apresenta o topo de sua árvore genealógica, a fundação da família Rivera: seus tataravós e a filha Inês (bisavó de Miguel), que viviam em harmonia com a música até o momento que o pai de Inês abandona a família e segue mundo afora com seu violão para perseguir 0 sonho de tornar-se cantor, sem nunca ter retornado ao seio familiar. Para lidar com a partida dele, mamá Amélia (mãe de Inês) elimina a música de suas vidas e, tendo que criar sua filha sozinha, começa a fabricar sapatos. 0 ofício de sapateiros é repassado de geração em geração até al cançar Miguel, o qual não apresenta interesse por sapataria e sim pela música.

Retornando ao tempo presente, Mamá Inês, bisavó de Miguel, já está em idade avançada e apresenta uma perda significativa de suas memórias. Sua filha, Elena Rivera, a abuelita de Miguel, éa matriarca da casa assim como outrora fora mamá Amélia. A abuelita é a guardiã dos costumes familiares e inclusive é quem assegura que a música permaneça exiliada de sua família. Apesar desse esforço, Miguel é desterritorializado desse campo e, considerando o que apresentamos anteriormente, há uma impossibilidade de extinção sonora (Wisnik, 2017) e, dessa forma, ele permanece envolvido pela música 
mantendo uma idolatria velada pelo músico já falecido e nacionalmente reconhecido "Ernesto de la Cruz" que, posteriormente, é confundido pelo protagonista como seu tataravô e papá de Inês. Ele é fonte de inspiração para Miguel e a música de maior sucesso e preferida do aspirante a cantor nomina-se "Lembre de mim"; uma música de melodia alegre e andamento rápido, cujo destaque será revelado ao final da animação.

Ressalta-se que, a despeito dos esforços de sua família em reprimir 0 acesso à música, o protagonista é um autodidata musical. A partir do diálogo com um mariachi, Miguel reflete sobre a importância de seguir seu desejo e ter coragem para assumi-lo para sua família uma vez que, sem essa audácia, terá que reproduzir os passos já destinados a ele na confecção de sapatos. Nesse aspecto, retomamos o que Winnicott (1971/2019) afirma em relação ao pathos da criatividade, que não diz respeito à ausência desta, mas a correlaciona a um falso self de quem não vive sua própria vida, e sim a vida alheia e submissa à vontade de outrem.

0 destino de Miguel era 0 de sobreviver em meio às escolhas de sua mamá Amélia e de seus descendentes, como um autômato que reproduz repetidamente e mecanicamente uma atividade. Contudo, viver criativamente é mais que sobreviver e, portanto, aceitar o ofício de sapateiro não traduz a verdade de Miguel. Assim, para alcançar seu sonho, ele rompe com sua família e lança-se no desconhecido em detrimento de atar-se aos caminhos pré-concebidos.

No Dia dos Mortos, as fotos dos ancestrais já falecidos são colocadas sobre um altar de oferendas de comidas (preferidas pelos entes) e flores (para guiar os espíritos pelas cores e perfumes) porque, segundo a crença popular e tradicional, nesse dia, esses espíritos lembrados pelas fotos, atravessam a ponte que separa o mundo dos vivos e mortos a fim de que possam visitar seus familiares. No topo do altar, respeitando a hierarquia familiar, encontra-se uma foto de mamá Inês ainda criança com seus pais. Contudo, a imagem de seu papá está rasgada e, assim como seu nome, deve ser esquecido pelos familiares e excluído das lembranças. Ressalta-se que, mesmo na escassa lucidez de mamá Inês, ela solicita seu pai na expectativa de que ele tenha retornado para ela ainda que os demais familiares Ihe tenham esquecido.

Verifica-se no filme, uma ênfase dada à família na constituição do indivíduo. Ela é guia e, portanto, é quem oferta as bases do desenvolvimento do sujeito. Dessa forma, retomamos Winnicott (1958/2011) no que diz respeito à importância de um ambiente suficientemente bom a fim de propiciar condições ao amadurecimento pessoal favoráveis às disposições hereditárias. Nesse sentido, não é possível pousar um olhar sobre Miguel como um indivíduo apartado de seu ambiente e, ante o exposto, justifica-se o papel relevante que a família constitui na vida do protagonista que, diante da imposição do ofício de sapateiro, precisa se apegar à legitimidade vocacional herdada de seu tataravô músico para romper os laços com os demais familiares em prol de sua sobrevivência psíquica.

Ainda que o filme não retrate os primórdios da infância de Miguel, uma vez que, no início, o infante tenha ascendido a uma integração favorecida pelo apoio egoico da mãe suficientemente boa, ele tem a possibilidade de atingir sua individualidade (Winnicott, 1953/2019). Nota-se, assim, uma capacidade de suportar a frustração perante a realidade externa, a qual é elucidada por meio da imposição do ofício de sapateiro, sem que o verdadeiro self do protagonista sucumba às intempéries inerentes ao viver e busque assim sua verdadeira vocação, a música.
Dessa forma, infere-se que, frente a uma sensação de despotencialização da vida, o protagonista não se paralisa, mas é capaz de se projetar a um futuro na medida em que há uma capacidade para estar só, já constituída pela disponibilidade da presença materna. Dessa maneira, ele pode prosseguir sua vida singular na descoberta de seus próprios caminhos.

A aceitação da alteridade expõe a realidade de um "eu" que se difere do outro e, portanto, se em princípio há uma dependência absoluta do bebê em relação à sua mãe, sendo um ser indiferenciado a ela, pouco a pouco, 0 desenvolvimento maturacional Ihe realça esses contornos, facilitando-Ihe 0 atravessamento pela dependência relativa rumo à independência (Winnicott, 1960/1983). Sob essa perspectiva, compreende-se que, nesse momento, em razão de seu apreço musical irrompido no seio familiar, Miguel passa a se reconhecer como um indivíduo distinto e capaz de viver autonomamente e não fusionado aos ideais familiares.

A dimensão musical do filme é bastante extensa e densa. Consegue transmitir a importância do fenômeno transicional, nesse estudo, o acalanto, como representante das relações primordiais e fundantes do psiquismo. Nos possibilita compreender, mesmo que figurativamente, o que remete à existência da chamada área transicional, caracterizada pelo potencial de abarcar tanto o mundo interno quanto externo (Winnicott, 1953/2019). Dessa maneira, não somente a música ocupa essa área na vida de Miguel, mas novamente esse fato é ratificado mediante um flashback em que se apresenta mamá lnês, ainda pequena, ouvindo um acalanto composto por seu pai e cantado diariamente pelos dois, antes de sua partida definitiva. Sublinha-se que esse acalanto é denominado "Lembre de mim"(Viva, 2017), anteriormente mencionado, mas dotado de significados diversos do apresentado anteriormente.

Ainda que a letra permaneça a mesma, a melodia melancólica e 0 andamento lento da música tornam a experiência musical completamente diferente da primeira, pois, nessa situação, verifica-se novamente que a ênfase é atribuída à melodia e harmonia da música e não à sua letra. Aparentemente sutil, esse aspecto é bastante relevante e o filme consegue captar a complexidade dessas nuances visto que a primeira versão da música é um sucesso nacional conhecido por todos os cidadãos, mas não tem força de evocação para a mamá Inês, agora idosa e confusa.

Dessa maneira, quando sua memória está se desvanecendo, o espectador presencia um sopro de lucidez que a retorna ao contato com a realidade externa através das lembranças de um passado remoto, ativadas pela cantiga reproduzida tal qual em sua infância. Isso nos remete à assertiva de Winnicott (1953/2019), o qual afirma que os fenômenos transicionais não são passíveis, necessariamente, de repressão e, portanto, podem perdurar nas lembranças. Ademais, a asserção remete ainda a proposição de Wolffenbüttel (2019), ao afirmar que na prática do acalanto as melodias costumam ser simples e suaves, além do que, sua execução evidencia o cuidado e o afeto, que podem ser lembrados mesmo na adultez.

A partir das considerações supracitadas, podemos afirmar, consequentemente, que o acalanto é um fenômeno transicional que produz uma ponte entre o mundo externo e o interno. Nota-se que na película também há uma ponte que une o mundo dos vivos e o mundo dos mortos em que 0 personagem pode ser metaforicamente compreendido como a própria ponte que liga e separa os dois mundos visto que, por um dia, ele não se encontra vivo nem morto, ainda que, paradoxalmente, esteja morto perante os vivos e vivo perante os mortos. 
No filme, apreende-se que a música não só conta uma história, mas, com seu vasto e precioso material, produz variadas histórias singulares a cada indivíduo e civilização em seu tempo, como aponta Machado (2012). Nesse sentido, a música se traduz em afeto, na possibilidade de fruição a partir do espaço potencial dilatado pelo brincar, bem como na transmissão da herança cultural, que são as experiências que antecedem o nascimento do indivíduo e que dizem respeito ao patrimônio cultural (Winnicott, 1953/2019).

Winnicott (1953/2019) afirma que a realidade nunca é aceita completamente em virtude da tensão ocasionada pelo liame entre mundo externo e interno. "É pela experiência da área intermediária" não contestada (área desenvolvida pelo brincar), ou seja, o campo relativo às artes, que o ser humano poderá aliviar essa tensão. Ademais, cabe a assertiva de que a música é também protagonista em cena. No encontro entre os dois protagonistas, a música é desencadeadora de transformações em Miguel que, sob bases constitutivas sólidas, pode assim alçar-se ao gesto espontâneo, a o verdadeiro self, ao viver criativo (Rodrigues \& Peixoto Junior, 2017; Winnicott, 1967/2019).

\section{Considerações finais}

Propor um diálogo entre Psicanálise e Música é tarefa árdua devido às suas especificidades e amplitudes, que ora convergem, ora divergem e que, em especial, demandam reflexões em um trânsito contínuo entre as áreas. Todavia, como testemunhamos a partir de nosso arcabouço teórico, elas enriquecem umas às outras. A Música percorre o indizível, o inefável e o imaterial, próprios ao inconsciente. Além disso, ainda que determinada música possa caracterizar um tempo e um espaço na sociedade, ela, em essência, carrega as características da atemporalidade e da universalidade nas civilizações que, desde os tempos primevos, manifestam uma presença musical em seu bojo.

0 acalanto opera por meio de uma relação com a alteridade, uma vez que o bebê, em princípio, não é capaz de se auto acalantar. Ademais, exerce a função de um dos primeiros objetos veiculadores da cultura com que a criança entra em contato. Enquanto fenômeno transicional, o acalanto encarna 0 amor das gerações que a sucederam e facilita a dilatação do espaço potencial do bebê ao produzir uma comunicação instalada no entrelaçamento do espaço potencial de ambos. A espontaneidade e a ludicidade, características presentes na atividade do acalanto, podem operar através do elo criado pelos espaços potenciais de cada um.

Dessa maneira, o conceito do espaço potencial forja, na constituição psíquica do sujeito, a possibilidade de viver criativamente. Ademais, enfatiza-se a relevância do tema proposto em nosso estudo que, por meio da utilização de fragmentos da animação Viva, elucida a potência do acalanto para a vida psíquica do sujeito. É, pois, a riqueza das experiências produzidas em um ambiente suficientemente bom que garantirá a possibilidade de um "vir a ser" dotado de um"colorido", tal qual nos evidenciou Winnicott (1957/1999).

Como apresentado, utilizamos fragmentos do filme Viva - a vida é uma festa, para ilustrarmos os nossos pressupostos sobre o acalanto e o viver criativo e, por meio da música - bem como em certa medida - também do cinema, pôde-se reafirmar a valia da fruição artística para a constituição de uma rica vida psíquica. Entende-se que o conceito de sublimação freudiano não abarca, de fato, de forma abrangente a questão da cultura e seus desdobramentos, devido a sua própria ambivalência nesse entorno. Vale mencionar que 0 acalanto, enquanto um fenômeno transicional é um dos aspectos pelo qual pode-se analisar a cultura e o material dela advindo. Contudo, há outros conceitos primordiais na Psicanálise, como o próprio complexo de Édipo, que permitem uma análise da cultura, sendo que este não foi foco do presente estudo e pode ser empregado como agenda para publicações futuras.

Paradoxalmente, para Winnicott, a herança cultural através da experiência humana adequada e localizada no espaço e tempo apropriados ao desenvolvimento, ofertadas pelo ambiente suficientemente bom, cria 0 potencial estado do devir. Assim sendo, em tempos de pandemia (Organização Mundial da Saúde [OMS], 2021; Wang, Horby, Hayden, \& Gao, 2020), verifica-se um aumento da demanda pelo consumo de manifestações artísticas na tentativa de, tal qual discorremos a respeito dos efeitos do acalanto, apaziguar o sofrimento psíquico. Dessa maneira, a experiência cultural é recurso que possibilita ao indivíduo encontrar saídas para um não-adoecimento e para proteger o self de uma desintegração frente à realidade externa hostil. Por fim, não considerada como uma "solução fácil" e nem como evitação às dificuldades, mas sim, como uma fonte de suporte para enfrentar o viver, que pode ser criativo e vir-a-ser.

\section{Referências}

Acalantar. (2020). In Michaelis. https://michaelis.uol.com.br/modernoportugues/busca/portugues-brasileiro/acalantar/.

Biørkvold, J. R. (2018a). As bases da formação do nasciturno. In Bjørkvold, J. R. Música, inspiração e criatividade: uma linguagem universal (pp.21-30). São Paulo: Summus.

Bjørkvold, J. R. (2018b). A criança lúdica aprende a viver. In Bjørkvold, J. R. Música, inspiração e criatividade: uma linguagem universal (pp.33-39). São Paulo: Summus.

Bjørkvold, J. R. (2018c). Música, inspiração e criatividade na sala de aula. In Bjørkvold, J. R. Música, inspiração e criatividade: uma linguagem universal (pp.139-144). São Paulo: Summus.

Figueiredo, L. C., \& Minerbo, M. (2006). Pesquisa em psicanálise: algumas ideias e um exemplo. Jornal de Psicanálise, 39(70), 257278. http://pepsic.bvsalud.org/scielo.php?script=sci_arttext\&pi$d=$ S0103-58352006000100017\&lng=pt\&tlng=pt.

Freeland, C. (2019a). Paradigmas e propósitos. In Freeland, C. Teoria da arte: uma breve introdução (pp.40-66). Porto Alegre: L\&PM Pocket.

Freeland, C. (2019b). Cognição, criação e compreensão. In Freeland, C. Teoria da arte: uma breve introdução (pp.146-170). Porto Alegre: L\&PM Pocket.

Freud, S. (2012). 0 interesse na psicanálise. In Freud, S. Obras Completas (pp.13-122). São Paulo: Companhia das Letras. (Texto originalmente publicado em 1913).

Freud, S. (2015). Arte, Literatura e os Artistas. Chaves, E. (Trad.). São Paulo: Autêntica editora.

Freud, S. (2015). 0 delírio e os sonhos da Gradiva de W. Jensen. In Freud, S. Obras Completas (pp.328-363). São Paulo: Companhia das Letras. (Texto originalmente publicado em 1907).

Fulgencio, L. (2016). Por que Winnicott? São Paulo: Zagodoni Editora.

Gay, P. (2012). Aplicações e implicações. In Gay, P. Freud: uma vida para o nosso tempo. (pp.314-364). São Paulo: Companhia das Letras.

Machado, S. A. P. (2012). Canção de ninar brasileira: aproximações. (Tese de doutorado, Faculdade de Filosofia, Letras e Ciências Humanas, Universidade de São Paulo).https://www.teses.usp.br/teses/disponiveis/8/8151/ tde-28082012-124302/publico/2012_SilviaDeAmbrosisPinheiroMachado_VRev.pdf

Organização Mundial da Saúde (OMS) (2021). Coronavirus Disease (COVID-19). https://covid19.who.int/ 
Quinodoz, J. M. (2007). Delírios e sonhos na "Gradiva" de Jensen (1907a). In Quinodoz, J. M. Ler Freud: guia de leitura da obra de S. Freud (pp.89-93). Porto Alegre: Artmed.

Rodrigues, J. M., \& Peixoto Junior, C. A. (2017). Sobre a noção de saúde decorrente da teoria do amadurecimento emocional de Donald Winnicott. Analytica, 6(11), 7-33. http://www.seer.ufsj.edu.br/index.php/analytica/ article/view/2667/1766

Vilete, E. (2013). Sobre a arte da psicanálise. São Paulo: Ideias \& Letras.

Viva - a vida é uma festa (2017). Coco (título original). Direção: Lee Unkrich e Adrian Molina. Produção: Darla K. Anderson e John Lasseter. Intérpretes: Anthony Gonzalez, Gael Garcia Bernal, Benjamin Bratt, Alana Ubach et al. Roteiro: Adrian Molina e Matthew Aldrich. EUA: Walt Disney Pictures e Pixar Animations Studios, 105 min., color.

Wang, C., Horby, P. W., Hayden, F. G., \& Gao, G. F. (2020). A novel coronavirus outbreak of global health concern. The Lancet, 395(10223), 470-473. https://doi.org/10.1016/S0140-6736(20)30185-9

Winnicott, D. W. (1983). Teoria do relacionamento paterno-infantil. In Winnicott, D. W. 0 ambiente e os processos de maturação: estudos sobre a teoria do desenvolvimento emocional (pp.38-54). Porto Alegre: Artmed. (Texto originalmente publicado em 1960).

Winnicott, D. W. (1999). Saber e aprender. In Winnicott, D. W. Os Bebês e suas mães (pp.13-18). São Paulo: Martins Fontes. (Texto originalmente publicado em 1957).

Winnicott, D. W. (2011). 0 primeiro ano de vida. Concepções modernas do desenvolvimento emocional. In Winnicott, D. W. A família e o desenvolvimento individual (pp.3-20). São Paulo: Martins Fontes. (Texto originalmente publicado em 1958).

Winnicott, D. W. (2019). A criatividade e suas origens. In Winnicott, D. W. 0 brincar e a realidade (pp.108-140). São Paulo: Ubu editora. (Texto originalmente publicado em 1971).

Winnicott, D. W. (2019). A localização da experiência cultural. In Winnicott, D. W. O brincar e a realidade (pp.154-166). São Paulo: Ubu editora. (Texto originalmente publicado em 1967).

Winnicott, D. W. (2019). 0 brincar: proposição teórica. In Winnicott, D. W. 0 brincar e a realidade (pp.69-90). São Paulo: Ubu editora. (Texto originalmente publicado em 1953).

Winnicott, D. W. (2019). Objetos transicionais e fenômenos transicionais. In Winnicott, D. W. Obrincar e a realidade (pp.13-51). São Paulo: Ubu editora. (Texto originalmente publicado em 1953).

Wisnik, J. M. (2017). Som, ruído e silêncio. In Wisnik, J. M. O som e o sentido: uma outra história das músicas (pp.17-70). São Paulo: Companhia das Letras.

Wolffenbüttel, C. R. (2019). Canções para embalar o sono: uma pesquisa sobre os acalantos. In Marques, C. A. \& Oliveira, R. G. (Orgs.). Processos educacionais e artísticos da performance musical: uma prática com propósito (pp.198-202). https://doi.org/10.22533/at.ed.19919281118 